\title{
Numerical investigation on phase separation in polymer-modified bitumen: effect of thermal condition
}

\author{
Jiqing Zhu ${ }^{1, *}$, Romain Balieu ${ }^{1}$, Xiaohu $\mathrm{Lu}^{2}$, and Niki Kringos ${ }^{1}$ \\ ${ }^{1}$ Department of Civil and Architectural Engineering, KTH Royal Institute of Technology, Brinellvägen 23, 10044 Stockholm, Sweden \\ ${ }^{2}$ Nynas $A B, 14982$ Nynäshamn, Sweden
}

Received: 3 October 2016

Accepted: 3 February 2017

Published online:

10 February 2017

(C) The Author(s) 2017. This article is published with open access at Springerlink.com

\begin{abstract}
With the aim to understand the effect of thermal condition on phase separation in polymer-modified bitumen (PMB), this paper numerically investigates four PMB binders under five thermal conditions between 140 and $180^{\circ} \mathrm{C}$. Based on a phase-field model previously developed by the authors for PMB phase separation, the updated model presented in this paper uses temperature-dependent parameters in order to approach the concerned temperature range, including mobility coefficients, interaction and dilution parameters. The model is implemented in a finite element software package and calibrated with the experimental observations of the four PMBs. The experimental results are well reproduced by the model, and it is thus believed that the calibrated parameters can represent the four PMBs. The simulation results indicate that the model proposed in this paper is capable of capturing the stability differences among the four PMBs and their distinct microstructures at different temperatures. Due to the transition of some PMBs from the thermodynamically stable state at $180{ }^{\circ} \mathrm{C}$ to the unstable state at $140{ }^{\circ} \mathrm{C}$, a homogenization process may occur during the cooling applied numerically. After the transition, the PMBs start to separate into two phases and gradually form the binary structures controlled by the temperature. It is indicated that the cooling rate slightly affects the final pattern of the PMB binary microstructure, although the process can be more complicated in reality due to the potential dynamic reasons.
\end{abstract}

\section{Introduction}

In order to balance the life-cycle cost and service performance of roads, polymer-modified bitumen (PMB) has been used as a high-performance material in many cases of road construction and maintenance [1-5]. However, there are still some challenges today that may limit the sustainable application of PMB [6, 7], especially in the fundamental aspects related to the polymer modification of paving bitumen. Among others, the potential

Address correspondence to E-mail: jiqing.zhu@abe.kth.se 
storage instability issue, which may occur in some PMBs with poor polymer-bitumen compatibility, is one of the identified common challenges for bitumen modification nowadays. This issue has a close relationship with the PMB phase separation behaviour during the storage and transport $[8,9]$, i.e. the separation of the polymer-rich phase from the bitumen-rich phase.

The phase separation behaviour of PMB is temperature-dependent. This means that a PMB may show different phase separation phenomena at different temperatures. At the storage temperature, the PMB phase separation behaviour reveals the storage stability. But at a lower temperature, it is closely related to the PMB morphology which may affect the binder properties at that temperature. Some previous studies [10-12] have indicated that the thermal condition has important influences on the PMB microstructure. This means that the temperature level and its changing rate can significantly affect the phase separation behaviour of a PMB. Nevertheless, a fundamental understanding on how these effects arise has still not yet been reached so far.

As the continuation of a preliminary exploration by the authors [13], this paper aims to understand the temperature dependency of PMB phase separation behaviour and numerically investigates the effects of thermal condition on PMB phase separation. The numerical model presented in this paper is based on the phase-field model proposed in [14] for describing and predicting PMB storage stability and phase separation behaviour. The temperature dependency of the model parameters is introduced in this paper, including that of the mobility coefficients, interaction and dilution parameters. The effect of thermal condition on PMB phase separation can thus be modelled and investigated through a numerical approach. The model is implemented for four different PMBs and calibrated with the experimental observations of the four PMBs (with 5\% styrene-butadiene-styrene copolymer by weight of the blends). The phase separation behaviour of the simulated PMBs is analysed under five different thermal conditions. The results of this study may assist in understanding the effects of thermal condition on PMB phase separation.

\section{Phase-field model for phase separation in PMB}

Phase-field method is a powerful approach to simulating the microstructure evolution of materials. In the research field of bituminous paving materials, this method has been increasingly employed as a tool to expand our fundamental understanding on material behaviours [14-17]. Among the recent reports, a phase-field model was proposed by the authors in [14] regarding PMB phase separation at the storage temperature. This model considers PMB as a pseudo-binary blend at the studied temperature $\left(180{ }^{\circ} \mathrm{C}\right)$, with a polymer-rich phase and a bitumenrich phase. The phase-field variable is the local volume fraction of the polymer modifier. This is a conserved phase-field variable. Its evolution is governed by the Cahn-Hilliard equation [18, 19], such that

$\frac{\partial \emptyset}{\partial t}=\nabla \cdot M(\emptyset) \nabla \frac{\delta F}{\delta \emptyset}$,

where $\emptyset$ is the local volume fraction of the polymer modifier in PMB; $t$ is the time; $\nabla$ is the Nabla operator; $M(\emptyset)$ is the mobility coefficient of the phase; and $F$ is the free energy of the PMB system. This phasefield model defines the mobility coefficient of the phase as a function of the local phase composition, which means that $M(\emptyset)$ depends on $\emptyset$ as well as the mobility coefficients of the polymer and bitumen. Under the incompressible condition, a linear dependency is used in the model, i.e.

$M(\emptyset)=M_{\mathrm{p}} \emptyset+M_{\mathrm{b}}(1-\emptyset)$,

where $M_{\mathrm{p}}$ is the mobility coefficient of the polymer modifier; and $M_{\mathrm{b}}$ is the mobility coefficient of the bitumen.

At high temperatures around the storage temperature, there is no coherent microstructure formed in common paving PMBs. Thus, there is no elastic energy or other forms of long-range free energy involved in this phase-field model for paving PMB phase separation. In this regard, the total free energy of the studied PMB system consists of the local free energy and gradient energy. The local free energy of the PMB system is the sum of the free energy of pure components (polymer and bitumen) and the free energy change due to mixing them. Using a common expression for the gradient energy density, the total free energy $F$ is formulated in the model as

$F=\int_{V}\left(f_{0}+\Delta f_{\mathrm{m}}+\frac{1}{2} \kappa|\nabla \emptyset|^{2}\right) \mathrm{d} V$,

where $V$ is the volume of the considered body; $f_{0}$ is the free energy density of the pure components (sum of polymer and bitumen); $\Delta f_{\mathrm{m}}$ is the free energy 
density change due to mixing; and $\kappa$ is the gradient energy coefficient.

For a given $\mathrm{PMB}$, the free energy of pure polymer and bitumen $\left(f_{0}\right)$ is dependent on the temperature and does not affect the minimization of the total free energy. The free energy of mixing for a PMB system can be represented by a double-well potential, such that

$\Delta f_{\mathrm{m}}=R T\left[\frac{z \emptyset}{N_{\mathrm{p}}} \ln (z \emptyset)+\frac{1-z \emptyset}{N_{\mathrm{b}}} \ln (1-z \emptyset)+z \emptyset(1-z \emptyset) \chi\right]$,

where $R$ is the universal gas constant; $T$ is the temperature; $z$ is the dilution parameter; $N_{\mathrm{p}}$ is the segment number of the polymer chains in the FloryHuggins lattice; $N_{\mathrm{b}}$ is the segment number of the hypothetical chains for bitumen in the Flory-Huggins lattice; and $\chi$ is the interaction parameter between polymer and the hypothetical chain for bitumen. This equation is a modified form of the Flory-Huggins free energy of mixing, with some simplifying assumptions made according to the fact that bitumen is a complex mixture of various molecules.

Overall, the mobility coefficient $M$ controls the speed of the separation in this phase-field model; the gradient energy coefficient $\kappa$ decides the interfacial tension and thickness between the phases; the segment numbers of the chains $\left(N_{\mathrm{p}}\right.$ for polymer chains and $N_{\mathrm{b}}$ for hypothetical chains of bitumen) introduce the influences of the molecular size and its distribution; the interaction parameter $\chi$ characterizes the degree of the polymer-bitumen interaction; and the dilution parameter $z$ is related to the swelling ratio of the polymer. It should be mentioned that $N_{\mathrm{b}}$ is not simply averaged approximation of all molecules in the bitumen. Rather it combines the effects of molecular size, distribution and their contributions to the configurational entropy. More details about this can be found in [14].

\section{Temperature dependency of the model parameters}

It has been indicated in [14] that the above-described model is capable of reproducing the phase separation behaviour of PMBs observed experimentally at the storage temperature $\left(180{ }^{\circ} \mathrm{C}\right)$. In order to extend the model for a concerned temperature range instead of a single temperature point, the temperature dependency of the model parameters is introduced into the model in this paper. Some of the model parameters are temperature-dependent, controlling the temperature dependency of the PMB phase separation behaviour. This paper considers the temperature dependency of the mobility coefficients $(M)$, interaction and dilution parameters $(\chi$ and $z$ ). As the temperature dependency of the gradient energy coefficient $(\kappa)$ may be quite weak [20,21], it is currently neglected in this paper.

Theoretically, the mobility coefficients of different materials (polymer and bitumen) are related to their self-diffusion coefficients. According to the reported temperature dependency of the self-diffusion coefficient in a general form [22, 23], this paper uses an Arrhenius temperature dependency for the mobility coefficients of polymer and bitumen, i.e.

$M=M_{0} \mathrm{e}^{-\frac{E}{R T}}$,

where $M$ is the mobility coefficient; $M_{0}$ is the maximum mobility coefficient at infinite temperature; and $E$ is the activation energy for mobility. Regarding the interaction parameter, it has been widely reported $[24,25]$ that the Flory-Huggins interaction parameter generally has the temperature dependency as

$\chi=\frac{\alpha}{T}+\beta$,

where $\alpha$ and $\beta$ are, respectively, constants for the enthalpic and entropic contributions to the interaction parameter $\chi$. As for the dilution parameter, it is related to the swelling ratio of the polymer modifier in PMB. Some researchers [26] have reported that the polymer swelling ratio increases slightly in $\mathrm{PMB}$, as the temperature increases. The dependency is approximately linear. This paper thus uses a simple linear dependency for the dilution parameter, such that

$z=k T+c$,

where $k$ and $c$ are constants.

\section{Numerical simulation results and discussion}

\section{Simulation environment and thermal conditions}

The finite element software COMSOL Multiphysics has been used to implement the model described in the previous sections. The geometry of the simulation 
domain is a rectangle of $2.5 \mathrm{~mm} \times 2.0 \mathrm{~mm}$ meshed with triangular elements. This domain is basically the same size as the microscopic images (magnification $50 \times)[11,12]$ that are used for calibration of the model parameters. As the boundary condition, the contact angle on the four sides of the rectangle is $90^{\circ}$. In order to present the initial state of the simulated PMB, normally distributed values are randomly located in the domain. The used mean value of the initial values is 0.05 , and the standard deviation is 0.005 . This means that the polymer content of the simulated PMB is $5 \%$ by weight with certain variation, if neglecting the polymer-bitumen density difference.

The phase separation behaviour is simulated under five different thermal conditions, numbered $1-5$ as in Fig. 1. They represent three different temperature levels (180, 160 and $140{ }^{\circ} \mathrm{C}$ ) and two cooling rates (fast cooling $8{ }^{\circ} \mathrm{C} / \mathrm{min}$ and slow cooling $2{ }^{\circ} \mathrm{C} / \mathrm{min}$ ) between 180 and $140{ }^{\circ} \mathrm{C}$. Of the investigated temperatures, $180{ }^{\circ} \mathrm{C}$ stands for a normal PMB storage temperature; $160{ }^{\circ} \mathrm{C}$ corresponds to a lower temperature for long-time $\mathrm{PMB}$ storage in order to avoid polymer degradation; and $140{ }^{\circ} \mathrm{C}$ may help to understand the effect of cooling during the construction process. All the simulations are run to apply the thermal conditions for $4800 \mathrm{~s}$.

\section{Model parameters and calibration}

Four different PMBs (numbered 1-4) are simulated in this paper with the intention of representing the four PMBs experimentally studied in [11, 12]. The four PMBs were prepared in laboratory with different base bitumen binders of penetration grade 70/100 from various sources, but they had the same styrenebutadiene-styrene copolymer modifier and the same polymer content ( $5 \%$ by weight of the blend). The modifier was a linear triblock copolymer. Its weight average molecular weight was $189,000 \mathrm{~g} / \mathrm{mol}$; the styrene content was about $30 \%$; and the fraction of triversus diblock copolymer was 0.8 .

The needed parameters for simulation include the maximum mobility coefficients $\left(M_{\mathrm{p} 0}\right.$ and $\left.M_{\mathrm{b} 0}\right)$, activation energies $\left(E_{\mathrm{p}}\right.$ and $\left.E_{\mathrm{b}}\right)$, gradient energy coefficient $(\kappa)$, segment numbers of the chains $\left(N_{\mathrm{p}}\right.$ and $\left.N_{\mathrm{b}}\right)$ and the constants $(\alpha, \beta, k$ and $c)$ for interaction and dilution parameters. In order to get the parameter values for the PMBs, the theoretical ranges of the model parameters are firstly discussed before fixing the specific values. After this, the specific values are calibrated within the theoretical ranges of the model parameters by the comparison between the experimental and numerical results.
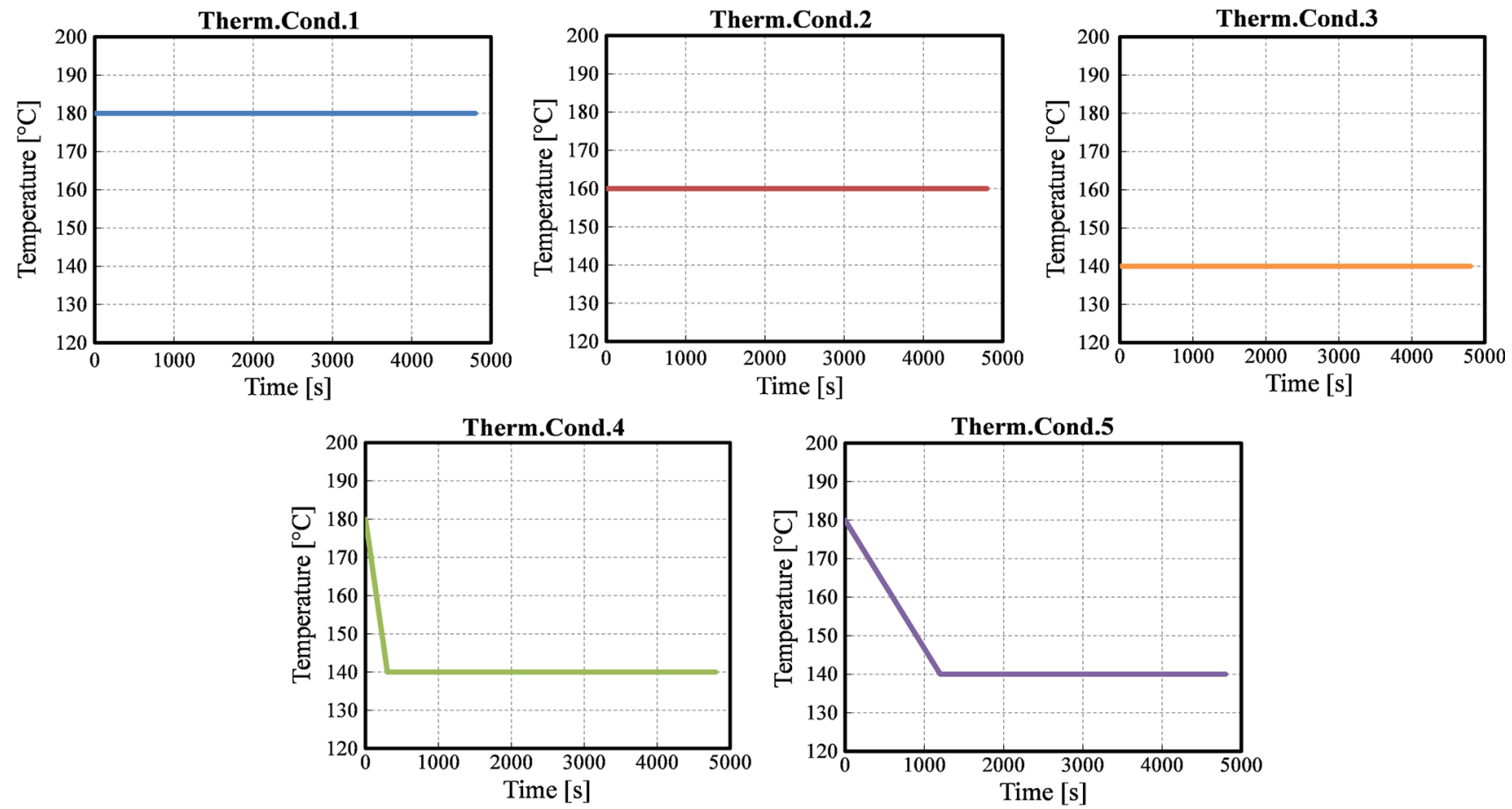

Figure 1 Thermal conditions applied in the simulations. 


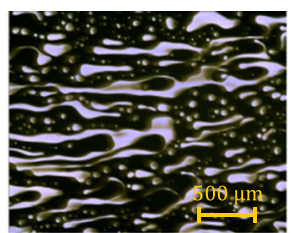

PMB $1,180^{\circ} \mathrm{C}, \mathrm{MO}$

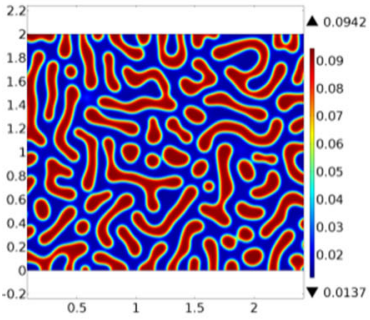

PMB1, $180^{\circ} \mathrm{C}, \mathrm{NS}$

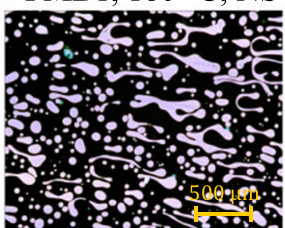

PMB $1,160^{\circ} \mathrm{C}, \mathrm{MO}$

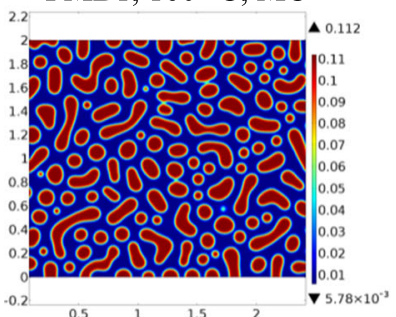

$\mathrm{PMB} 1,160^{\circ} \mathrm{C}, \mathrm{NS}$

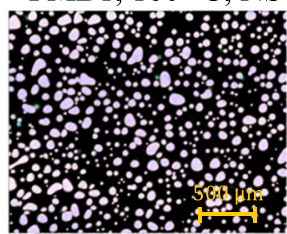

$\mathrm{PMB} 1,140{ }^{\circ} \mathrm{C}, \mathrm{MO}$

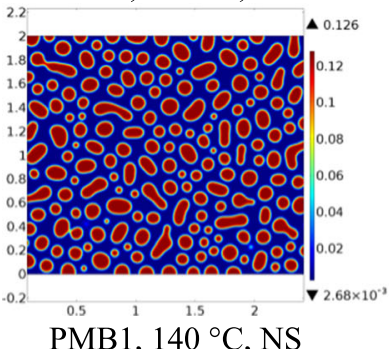

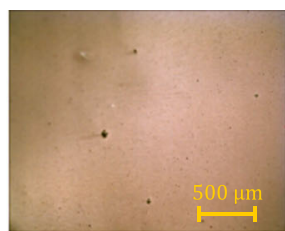
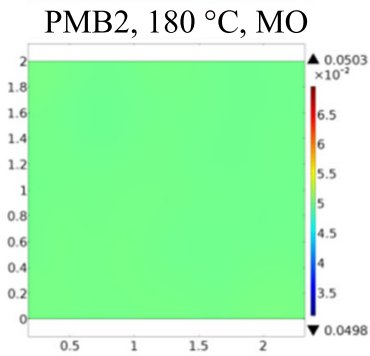

$\mathrm{PMB} 2,180^{\circ} \mathrm{C}$, NS
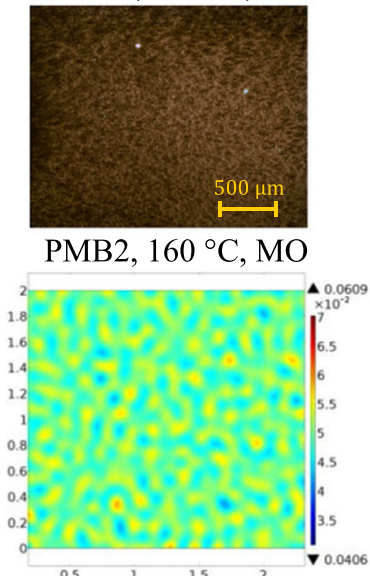

$\mathrm{PMB} 2,160^{\circ} \mathrm{C}$, NS

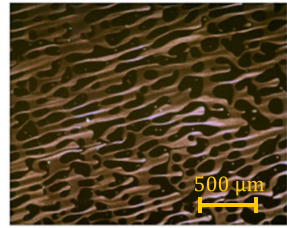

$\mathrm{PMB} 2,140{ }^{\circ} \mathrm{C}, \mathrm{MO}$

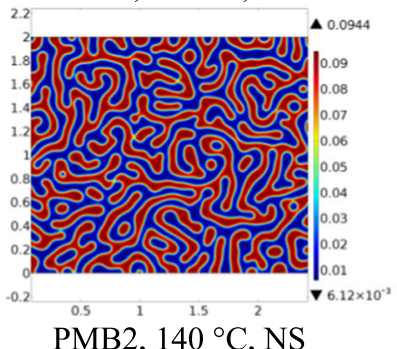

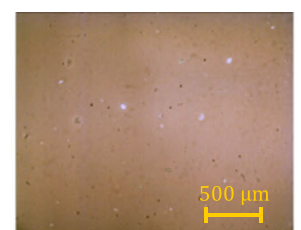
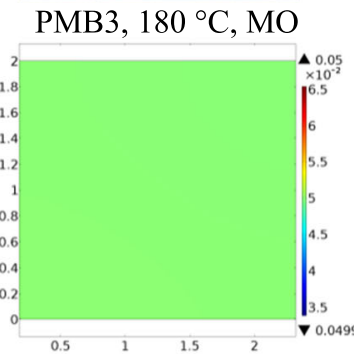

PMB3, $180^{\circ} \mathrm{C}$, NS

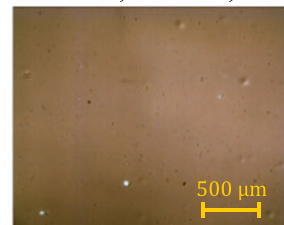

PMB3, $160{ }^{\circ} \mathrm{C}, \mathrm{MO}$

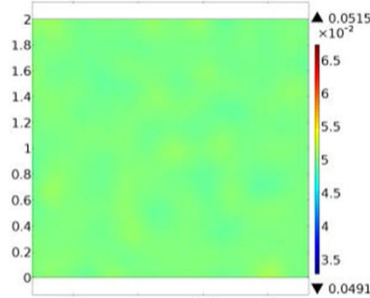

PMB3, $160^{\circ} \mathrm{C}$, NS

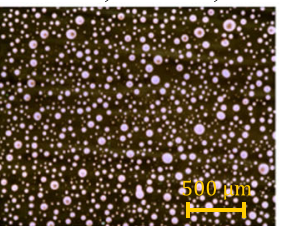

PMB3, $140{ }^{\circ} \mathrm{C}, \mathrm{MO}$

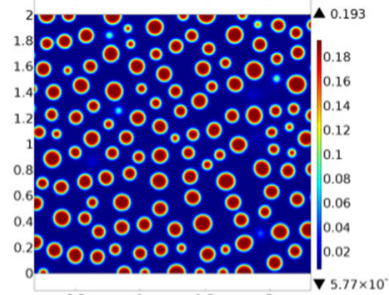

PMB3, $140^{\circ} \mathrm{C}$, NS

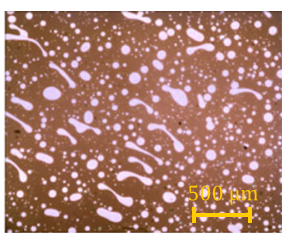

PMB4, $180^{\circ} \mathrm{C}, \mathrm{MO}$

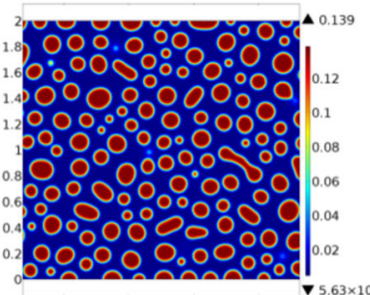

PMB4, $180^{\circ} \mathrm{C}$, NS

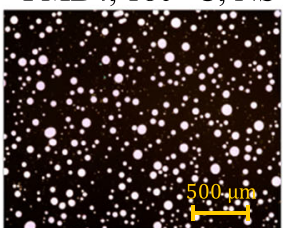

PMB4, $160{ }^{\circ} \mathrm{C}, \mathrm{MO}$

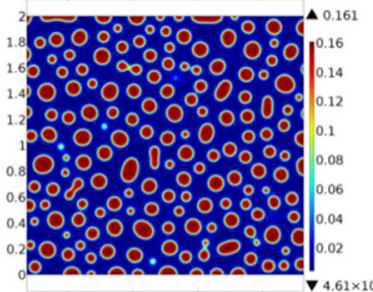

PMB4, $160^{\circ} \mathrm{C}$, NS

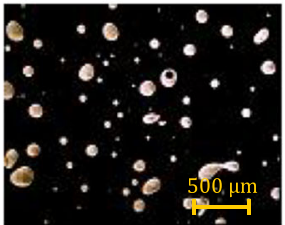

PMB4, $140{ }^{\circ} \mathrm{C}, \mathrm{MO}$

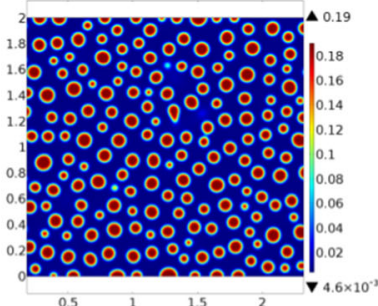

PMB $4,140^{\circ} \mathrm{C}$, NS

Figure 2 Microscopy observation (MO) and numerical simulation (NS) results of the four different PMBs at $3600 \mathrm{~s}$.

Table 1 Calibrated model parameters for the four PMBs

\begin{tabular}{llllllr}
\hline Samples & $M_{\mathrm{b} 0}\left[\mathrm{~m}^{5} /(\mathrm{J} \mathrm{s})\right]$ & $E_{\mathrm{b}}(\mathrm{J} / \mathrm{mol})$ & $\alpha(\mathrm{K})$ & $\beta$ & $k\left(\mathrm{~K}^{-1}\right)$ & \multicolumn{1}{c}{$c$} \\
\hline PMB1 & $2.1 \times 10^{-14}$ & $2.7 \times 10^{4}$ & $6.5 \times 10^{3}$ & -11.8 & $3.75 \times 10^{-2}$ & -7.7 \\
PMB2 & $2.0 \times 10^{-13}$ & $3.7 \times 10^{4}$ & $7.6 \times 10^{3}$ & -15.4 & $2.50 \times 10^{-3}$ & 8.9 \\
PMB3 & $2.3 \times 10^{-14}$ & $2.3 \times 10^{4}$ & $1.6 \times 10^{4}$ & -34.9 & $1.80 \times 10^{-1}$ & -69.3 \\
PMB4 & $1.2 \times 10^{-16}$ & $7.1 \times 10^{3}$ & $2.8 \times 10^{3}$ & -2.7 & $4.50 \times 10^{-2}$ & -13.4 \\
\hline
\end{tabular}


Figure 3 Variations of mobility coefficients with temperature.

Figure 4 Variations of interaction parameters with temperature.

Figure 5 Variations of dilution parameters with temperature.
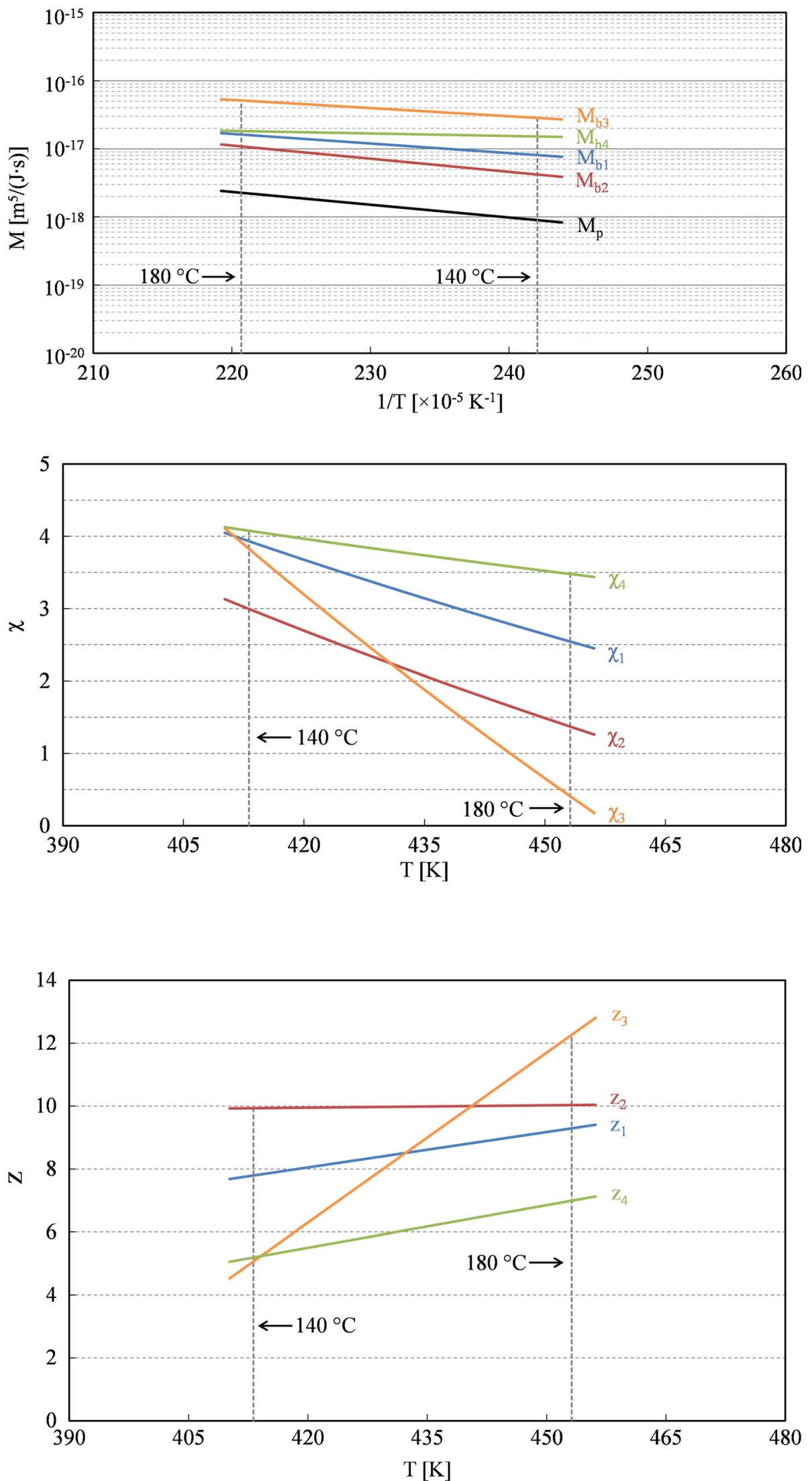
Since some of the needed PMB parameters are not commonly measured for the time being, the used ranges of $M_{\mathrm{p} 0}, M_{\mathrm{b} 0}, E_{\mathrm{p}}, E_{\mathrm{b}}$ and $\kappa$ in this paper are estimated based on the reported parameter values for general phase-field models and other materials like polymer blends and alloys [27-30]. For $N_{\mathrm{p}}$ and $N_{\mathrm{b}}$, it is postulated that the hypothetical chains for bitumen have the same length as the polymer chains. This does not mean that the bitumen has the same molecular size as the polymer chains. But the complexity of bitumen composition, due to its diversity in chemical species, has the same contribution to the configurational entropy as the polymer chains. In other words, $N_{\mathrm{b}}$ is not the actual value of the bitumen molecular weight but a parameter representing the complexity of the bitumen composition. By setting $N_{\mathrm{p}}=N_{\mathrm{b}}=N$, the parameter $N \chi$ scales up into the widely reported theoretical range where $N \chi \leq 2.0$ results in a single well and $N \chi>2.0$ leads to a double well [31-34]. Thus, the values of $\alpha$ and $\beta$ can be obtained according to the estimated $N \chi$ values. In this sense, the parameters $\alpha$ and $\beta$ discussed in this paper also indicate the influences of the molecular size and its distribution (they have in fact the values of $N \alpha$ and $N \beta$ ). As for the dilution parameter, the values of $k$ and $c$ can be estimated on the basis of the reported swelling ratio values of the polymer modifiers in PMBs $[26,35,36]$.

Microscopy observation results from [11, 12] are used as the experimental corroboration for model calibration in this paper. As presented in Fig. 2, the microscopy images display the microstructure of the four PMBs after one hour isothermal annealing at three different temperatures. It can be seen from the microscopy observation (MO) results in Fig. 2 that the four PMBs show different phase separation behaviours. PMB1 and PMB4 separate into two phases at $180{ }^{\circ} \mathrm{C}$ (the lighter polymer-rich phase and the darker bitumen-rich phase), while PMB 2 and PMB3 remain homogeneous at this scale. At $140{ }^{\circ} \mathrm{C}$, all the PMBs show two-phase structures but the patterns are different. For each of the PMBs, the microstructure changes as the temperature varies between 180 and $140{ }^{\circ} \mathrm{C}$.

In order to calibrate the model parameters for the four PMBs, the model described in the previous sections is implemented to reproduce these microscopy observation results. The numerical simulations represent the same condition as the experimental procedure in [11, 12]. The calibrated model parameters are shown in Table 1, together with $M_{\mathrm{p} 0}=3.2 \times 10^{-14} \mathrm{~m}^{5} /(\mathrm{J} \mathrm{s}), \quad E_{\mathrm{p}}=3.6 \times 10^{4} \mathrm{~J} / \mathrm{mol}$ and $\kappa=4.50 \times 10^{-5} \mathrm{~J} / \mathrm{m}$. With these values, the numerical simulation (NS) results for the four PMBs are also shown in Fig. 2, following the microscopy images. It is indicated that the phase separation behaviours of the PMBs are well reproduced by the model with the calibrated parameter values, including the stability differences between the PMBs and the microstructure differences between different temperatures. Thus, it is believed that the listed parameters in Table 1 can describe the phase separation behaviours of the four PMBs properly.

With the calibrated parameter values, the variations of the mobility coefficients, interaction and dilution parameters with temperature are plotted as in Figs. 3, 4 and 5. It can be seen in Fig. 3 that the base bitumen binders have higher mobility coefficients than the polymer within the discussed temperature range. The mobility coefficients decrease as the temperature decreases. Figure 4 shows that the interaction parameters decrease as the temperature increases, which means that the polymer and base bitumen binders are more interactive with each other at higher temperatures. It is indicated in Fig. 5 that the dilution parameters increase as the temperature increases. This means that the relative amount of the interactive molecules in the base bitumen binders becomes higher (and the polymer swells more) when the temperature rises. All the PMBs have different temperature dependencies for each of the discussed parameters, showing the different material properties among the PMBs. Based on these numerical results, it is thus believed that the calibrated parameter values generally describe reasonable material properties. This also confirms that the parameter values listed in Table 1 can accurately represent the four investigated PMBs. However, it is worth mentioning that all the listed values are only valid for the studied temperature range, i.e. $140-180^{\circ} \mathrm{C}$. Beyond this range, more discussions are still needed.

The calibrated parameter values also give the free energy curves by Eq. 4. Consequently, a theoretical phase diagram of the four PMBs can be computed on the basis of the free energy curves. By plotting the free energy minimum points at different temperatures, the computed phase diagram of the four PMBs (the binodal curves) is obtained and presented in Fig. 6. This phase diagram reveals the phase separation behaviours of the four PMBs within the studied 


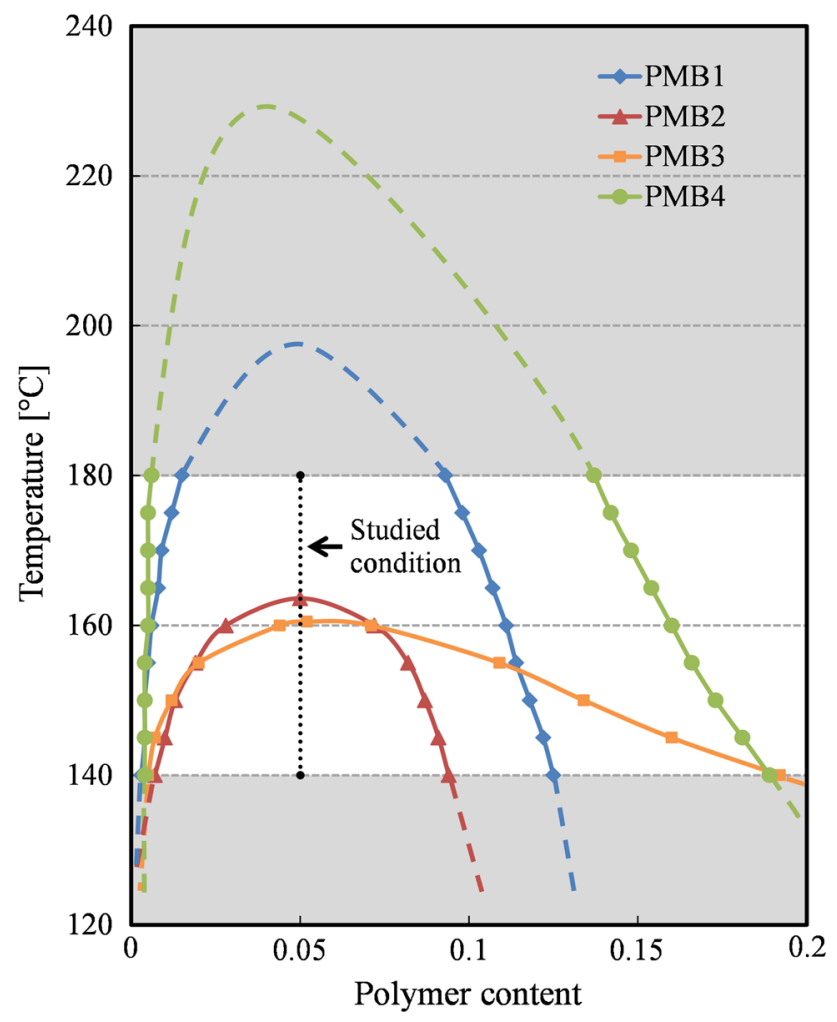

Figure 6 Computed phase diagram of the four PMBs.

temperature range and can serve as the analytical solutions for the simulations. It will be discussed with the numerical simulation results in the following sections of this paper.

\section{Effect of temperature level}

The simulation results with Therm.Cond.1-3 (180, 160 and $140{ }^{\circ} \mathrm{C}$ ) are shown in Figs. 7, 8 and 9, respectively. The results disclose the influence of temperature level on phase separation behaviour of the simulated PMBs. It can be seen in Fig. 7 that PMB1 and PMB4 separate into two phases at $180{ }^{\circ} \mathrm{C}$ (warmer colours for the polymer-rich phase and cooler colours for the bitumen-rich phase), while PMB 2 and PMB3 have homogeneous structures even after the high-temperature storage. According to Fig. 4, the interaction parameters of PMB1 and PMB4 are greater than 2.0 at $180{ }^{\circ} \mathrm{C}$. Thus, their free energy curves are double wells at $180{ }^{\circ} \mathrm{C}$, indicating their thermodynamic instability under Therm.Cond.1. In contrast, PMB2 and PMB3 have interaction parameters less than 2.0, leading to their single-well free energy curves and thermodynamic stability under Therm.Cond.1.
For the unstable PMB1 and PMB4, different patterns are shown in the simulation results with Therm.Cond.1. The polymer-rich phase forms threads in PMB1 but droplets in PMB4. This means the different base bitumen binders in PMB1 and PMB4 result in different swelling ratios of the polymer modifier, in spite of the same polymer content. According to Fig. 5, PMB1 has a higher dilution parameter than PMB4, showing a higher number of interactive molecules in the base bitumen of PMB1 than PMB4. This leads to the higher swelling ratio of the polymer in PMB1. In addition, Fig. 7 gives the same values of equilibrium phase composition for the PMBs as indicated in Fig. 6.

As the temperature decreases, PMB1 and PMB4 keep the two-phase structures but PMB2 and PMB3 become thermodynamically unstable through a stability-instability transition, shown in Figs. 8 and 9. A lower temperature can only affect the microstructure and composition of the equilibrium phases in PMB1 and PMB4. But the temperature drop from 180 to $140{ }^{\circ} \mathrm{C}$ changes the stability of PMB2 and PMB3. At $140{ }^{\circ} \mathrm{C}, \mathrm{PMB} 2$ and PMB3 have interaction parameters greater than 2.0 according to Fig. 4 . This results in the double wells on their free energy curves and causes their phase separations under Therm.Cond.3. PMB2 and PMB3 show different patterns in Fig. 9: a bicontinuous structure for PMB2 but a droplet pattern with a continuous matrix for PMB3. This can be attributed to the higher swelling ratio of the polymer in PMB2 than PMB3 at $140{ }^{\circ} \mathrm{C}$, which is controlled by the dilution parameters as presented in Fig. 5. With Therm.Cond.2, Fig. 8 displays the intermediate states of the PMBs during the thermodynamic transition between 180 and $140{ }^{\circ} \mathrm{C}$.

In Fig. 9, it is interesting to see that PMB3 and PMB4 show similar microstructures at $140{ }^{\circ} \mathrm{C}$, although their phase structures are completely different with each other at other temperatures (as in Figs. 7,8 ). This can be interpreted by the computed phase diagram Fig. 6. At $180{ }^{\circ} \mathrm{C}$, PMB3 lies in the one-phase regime of its phase diagram, but PMB4 is most possibly in its unstable regime. At $160{ }^{\circ} \mathrm{C}$, the bimodal points of PMB3 are far away from those of PMB4. However, they come to almost the same locations at $140{ }^{\circ} \mathrm{C}$. The different material parameters of PMB3 and PMB4 (as in Table 1) decide the different temperature dependencies of their phase separation behaviour. All these differences are expressed by the model and presented in the numerical 


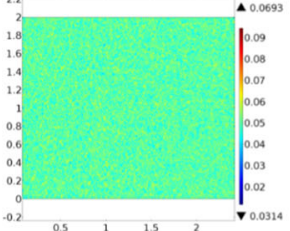

PMB1, Therm.Cond.1 $0 \mathrm{~s}$

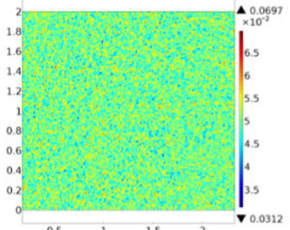

PMB2, Therm.Cond.1 $0 \mathrm{~s}$

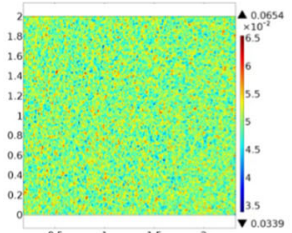

PMB3, Therm.Cond. 1

$0 \mathrm{~s}$

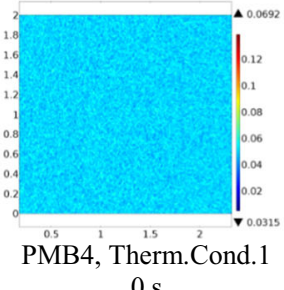

$0 \mathrm{~s}$

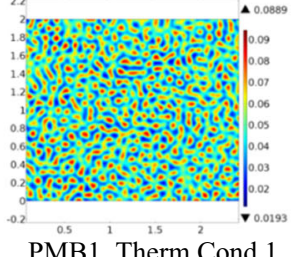
$300 \mathrm{~s}$

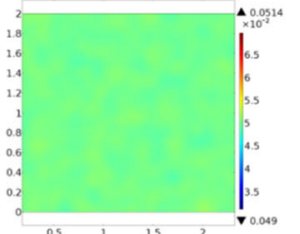

PMB2, Therm. Cond. 1 $300 \mathrm{~s}$

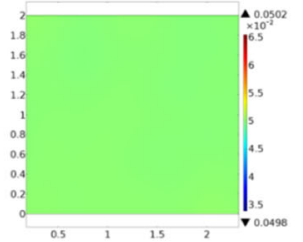

PMB3, Therm.Cond. 1 $300 \mathrm{~s}$

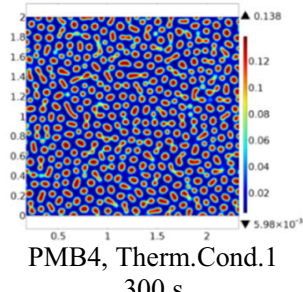

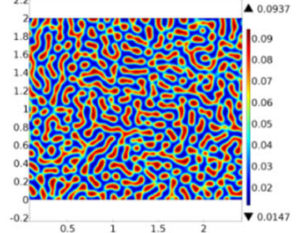

PMB1, Therm. Cond.1 $600 \mathrm{~s}$

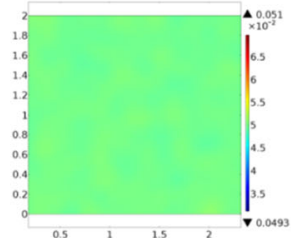

PMB2, Therm. Cond. 1 $600 \mathrm{~s}$

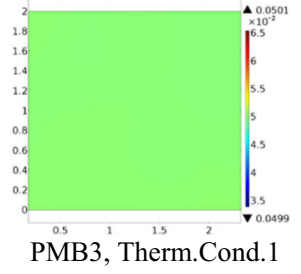
$600 \mathrm{~s}$

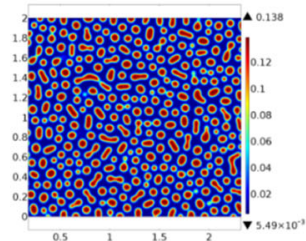

PMB4, Therm. Cond.1 $600 \mathrm{~s}$

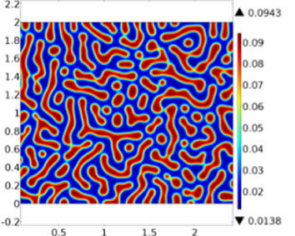

PMB1, Therm. Cond. 1 $1800 \mathrm{~s}$

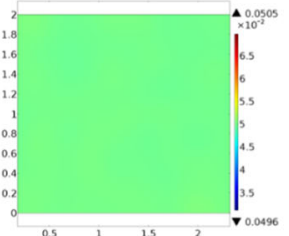

PMB2, Therm. Cond. 1 $1800 \mathrm{~s}$

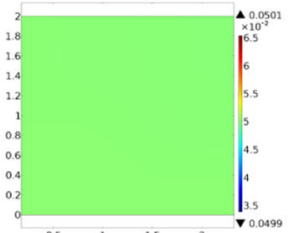

PMB3, Therm.Cond. 1 $1800 \mathrm{~s}$

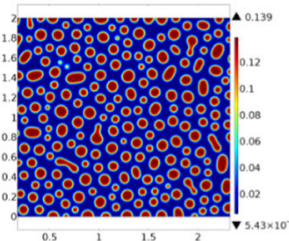

PMB4, Therm. Cond. 1 $1800 \mathrm{~s}$

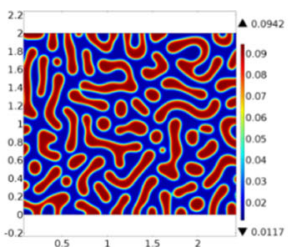

PMB1, Therm.Cond.1 $4800 \mathrm{~s}$

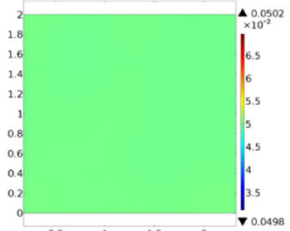

PMB2, Therm. Cond.1 $4800 \mathrm{~s}$

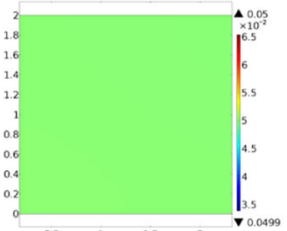

PMB3, Therm. Cond.1 $4800 \mathrm{~s}$

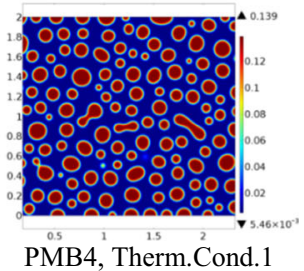

$4800 \mathrm{~s}$

Figure 7 Numerical simulation results with Therm.Cond. $1\left(180^{\circ} \mathrm{C}\right)$.

simulation results. The same also applies for PMB1 and PMB2, and probably all PMBs.

\section{Effect of cooling rate}

The effect of temperature level on PMB phase separation behaviour is discussed in the previous section. However, PMB phase separation is essentially a time-dependent microstructure evolution process. Consequently, the changing rate of the temperature may also have its influence on PMB phase separation behaviour. Therm.Cond. 4 and Therm.Cond.5 aim to investigate the effect of cooling rate on phase separation behaviour of the simulated PMBs. The simulation results are shown in Figs. 10, 11, 12, 13 and 14.

In Fig. 10, it can be seen that PMB1 and PMB4 approximately follow a similar evolution routine as under the previous thermal conditions, although the fast cooling has its impacts on the separation process and the final PMB microstructure. But a homogenization process occurs in PMB2 and PMB3 during the fast cooling between 0 and $300 \mathrm{~s}$. This homogenization process is due to the transition of the PMBs from a thermodynamically stable state to a thermodynamically unstable state during the cooling. After the homogenization, PMB2 and PMB3 start to separate and form the binary structures at $140{ }^{\circ} \mathrm{C}$.

Since the model presented in this paper uses fixed material property parameters for a fixed temperature (e.g. $140{ }^{\circ} \mathrm{C}$ ), it is not unexpected that the same temperature leads to the same equilibrium phase composition and polymer swelling ratio. As a consequence, the final patterns of the PMB binary structures in Fig. 10 are quite similar as those in Fig. 9, though not exactly the same. The final values of the local polymer volume fraction in the equilibrium phases in Fig. 10 are the same as the final values in Fig. 9, essentially controlled by the phase diagram of the four PMBs as Fig. 6. However, the process can be more complicated in reality due to the potential 


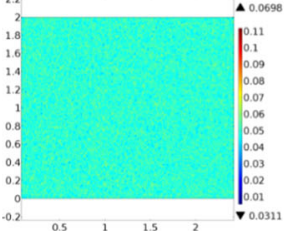

PMB1, Therm.Cond.2 $0 \mathrm{~s}$

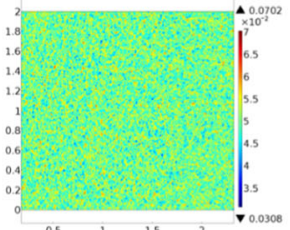

PMB2, Therm.Cond.2 $0 \mathrm{~s}$

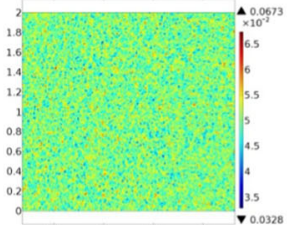

PMB3, Therm. Cond.2

$0 \mathrm{~s}$

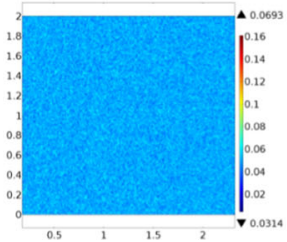

PMB4, Therm. Cond. 2

$0 \mathrm{~s}$

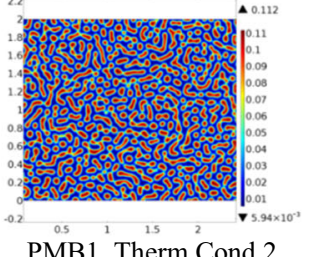

$300 \mathrm{~s}$

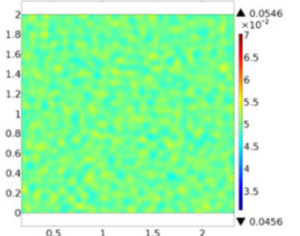

PMB2, Therm. Cond.2 $300 \mathrm{~s}$

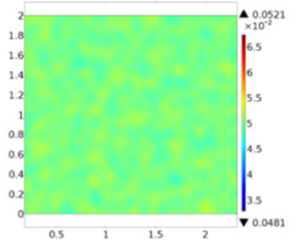

PMB3, Therm. Cond.2 $300 \mathrm{~s}$

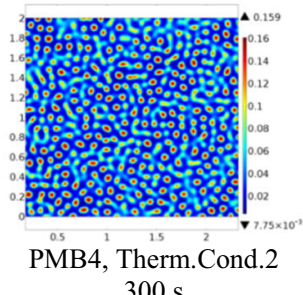

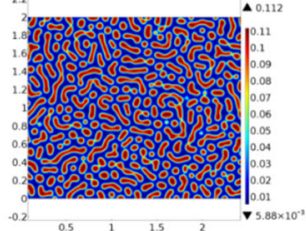

PMB1, Therm.Cond.2 $600 \mathrm{~s}$
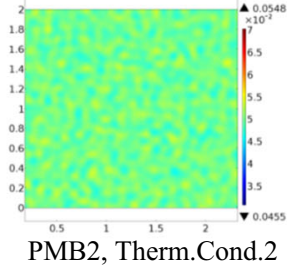
$600 \mathrm{~s}$

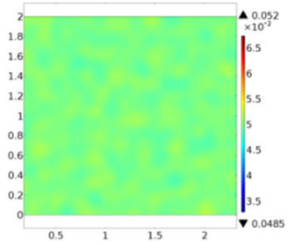

PMB3, Therm.Cond. 2 $600 \mathrm{~s}$

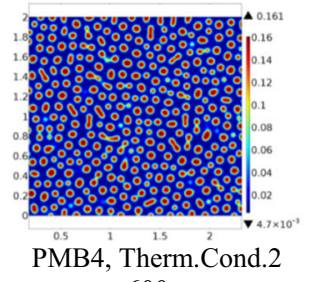

$600 \mathrm{~s}$

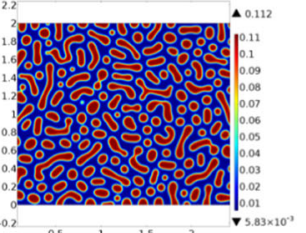

PMB1, Therm.Cond.2 $1800 \mathrm{~s}$

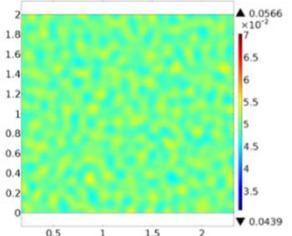

PMB2, Therm. Cond. 2 $1800 \mathrm{~s}$

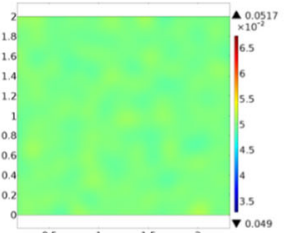

PMB3, Therm. Cond. 2 $1800 \mathrm{~s}$

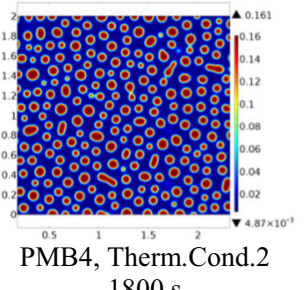

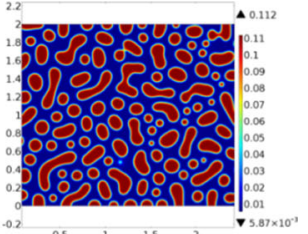

PMB1, Therm.Cond.2 $4800 \mathrm{~s}$

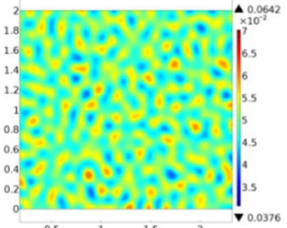

PMB2, Therm.Cond.2 $4800 \mathrm{~s}$

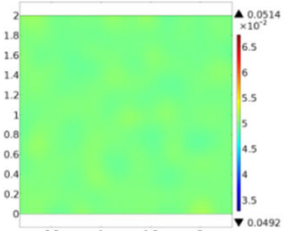

PMB3, Therm. Cond. 2 $4800 \mathrm{~s}$

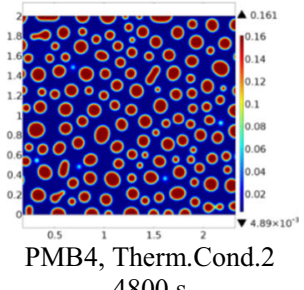

Figure 8 Numerical simulation results with Therm.Cond. $\left(160{ }^{\circ} \mathrm{C}\right)$.

effects of the interfacial tension, material viscosity and rheology.

Figures 11, 12, 13 and 14 show the PMB structure evolution processes under Therm.Cond.5 (with a lower cooling rate). According to Figs. 11 and 14, both PMB1 and PMB4 start to separate from the very beginning of the simulated process. The results in Figs. 11 and 14 indicate the influence of the bimodal point change (Fig. 6) of the PMBs during the cooling. After the cooling termination at $1200 \mathrm{~s}$, the PMBs reach the equilibrium states shown in Fig. 6 but the final microstructures are slightly affected by the cooling rate.

As for PMB2 and PMB3, Fig. 6 reveals that their stability-instability transitions both occur between 170 (300) and $160{ }^{\circ} \mathrm{C}$ (600 s). Before the transitions, Figs. 12 and 13 show that they form more homogenous structures than the initial ones. After the homogenization, the separation processes start and the PMBs gradually form the binary structures. As the phase separations start from more homogenized structures under Therm.Cond.5 than Therm.Cond.4, it takes longer time for the PMBs to reach the equilibrium states under Therm.Cond.5. By $2100 \mathrm{~s}(900 \mathrm{~s}$ after the cooling terminated), PMB3 has not displayed a two-phase structure in Fig. 13. At the end of the simulated process, PMB2 and PMB3 reach the equilibrium states shown in Fig. 6. However, the cooling rate only slightly affects the final patterns of the PMBs' binary structures in this paper.

\section{Swelling ratio during separation}

With the simulation results, the polymer-rich phase of a PMB can be defined as the area where the local polymer volume fraction is higher than the mean of the initial values (5\% in this paper). Thus, the polymer swelling ratio can be defined as the ratio between 


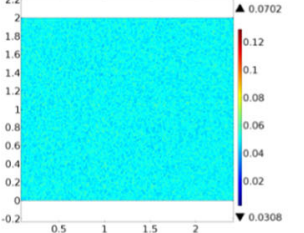

PMB1, Therm.Cond.3 $0 \mathrm{~s}$

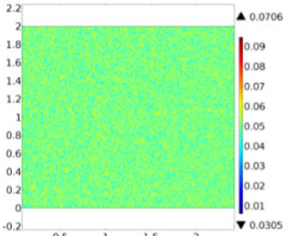

PMB2, Therm.Cond.3 $0 \mathrm{~s}$

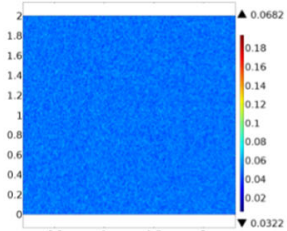

PMB3, Therm.Cond. 3

$0 \mathrm{~s}$

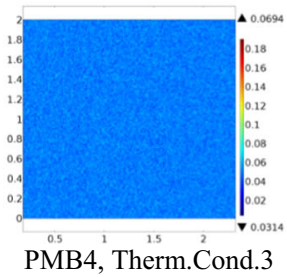

$0 \mathrm{~s}$

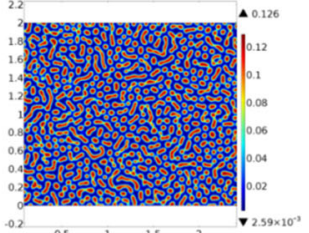

PMB1, Therm.Cond.3 $300 \mathrm{~s}$

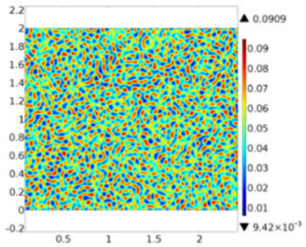

PMB2, Therm.Cond.3 $300 \mathrm{~s}$

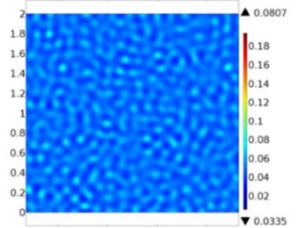

PMB3, Therm. Cond. 3 $300 \mathrm{~s}$

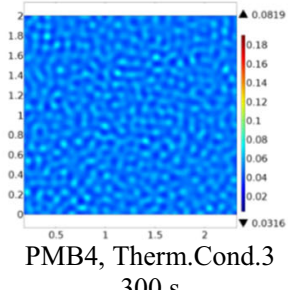

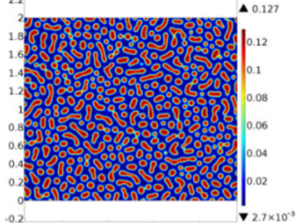

PMB1, Therm.Cond.3 $600 \mathrm{~s}$

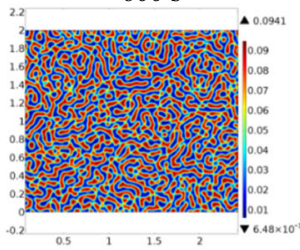

PMB2, Therm. Cond. 3 $600 \mathrm{~s}$

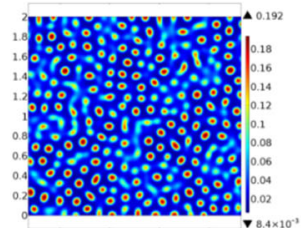

PMB3, Therm. Cond. 3 $600 \mathrm{~s}$

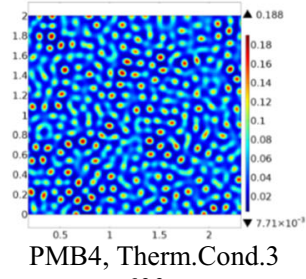

$600 \mathrm{~s}$

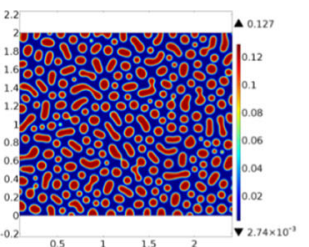

PMB1, Therm.Cond. 3 $1800 \mathrm{~s}$

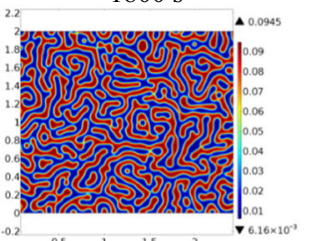

PMB2, Therm. Cond.3 $1800 \mathrm{~s}$

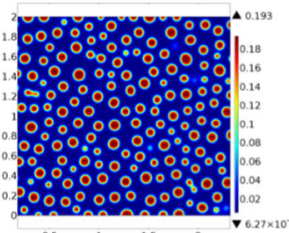

PMB3, Therm.Cond. 3 $1800 \mathrm{~s}$

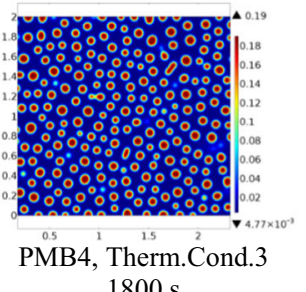

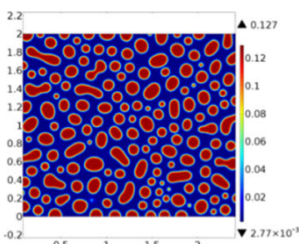

PMB1, Therm.Cond.3 $4800 \mathrm{~s}$

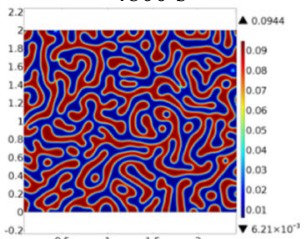

PMB2, Therm.Cond.3 $4800 \mathrm{~s}$

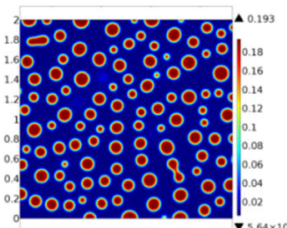

PMB3, Therm.Cond.3 $4800 \mathrm{~s}$

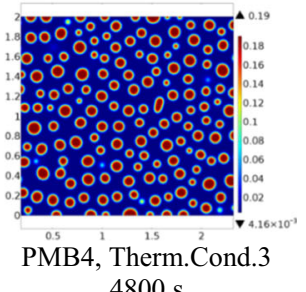

Figure 9 Numerical simulation results with Therm.Cond.3 $\left(140{ }^{\circ} \mathrm{C}\right)$.

the area fraction of the polymer-rich phase and the mean of the initial values. By post-processing the numerical results, the swelling ratio values during the whole simulated process can be obtained, as shown in Fig. 15 for the thermodynamically unstable cases. Because of the normal distribution of the initial values, all the curves in Fig. 15 start from the swelling ratio value of 10 , representing the sufficient swelling of the polymer in the beginning. At the end of the simulated process, it is the temperature that determines the final value of polymer swelling ratio for each of the PMBs. A higher temperature leads to a higher polymer swelling ratio, while Therm.Cond.3, 4 and 5 tend to finalize with the same value.

However, the variations of the swelling ratio values at the early stage can provide explicit information on the process of reaching the equilibrium state from the initial state. It can be seen in Fig. 15a that the polymer swelling ratios of both PMB1 (blue lines) and PMB4 (green lines) gradually decrease until the final values are reached under all the studied thermal conditions. The differences between the thermal conditions lie on the time needed to reach the equilibrium state. Among Therm.Cond.1, 2 and 3, PMB1 and PMB4 show different effects of the temperature on the changing rate of the polymer swelling ratio at the beginning stage. This might depend on their different material property parameters. But all the curves with cooling follow the middle paths between 180 and $140{ }^{\circ} \mathrm{C}$. For both PMBs, the slow cooling curves follow the $180^{\circ} \mathrm{C}$ curves for longer time and reach the equilibrium at $140{ }^{\circ} \mathrm{C}$ later than the fast cooling curves.

As for PMB2 (red lines) and PMB3 (orange lines), Fig. 15b gives only the curves under Therm.Cond.3, 4 and 5, since neither PMBs show definite instability at 180 or $160{ }^{\circ} \mathrm{C}$ (no typical polymer-rich phase). Under Therm.Cond.3, PMB3 presents a representative curve for unstable PMBs in Fig. 15b, similar as those of PMB1 and PMB4 in Fig. 15a. However, with cooling 


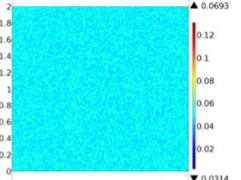

PMB1, Therm. Cond. 4 $0 \mathrm{~s}, 180{ }^{\circ} \mathrm{C}$

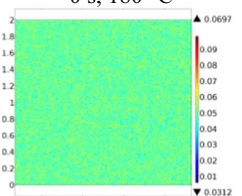

PMB2, Therm. Cond. $0 \mathrm{~s}, 180{ }^{\circ} \mathrm{C}$

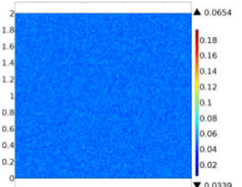

PMB3, Therm. Cond. 4 $0 \mathrm{~s}, 180^{\circ} \mathrm{C}$

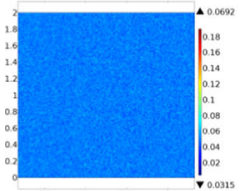

PMB4, Therm. Cond 4 $0 \mathrm{~s}, 180^{\circ} \mathrm{C}$

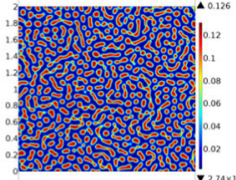

PMB1, Therm.Cond.4 $300 \mathrm{~s}, 140{ }^{\circ} \mathrm{C}$

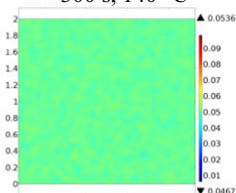

PMB2, Therm. Cond. 4 $300 \mathrm{~s}, 140^{\circ} \mathrm{C}$

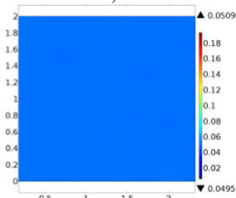

PMB3, Therm. Cond. 4 $300 \mathrm{~s}, 140{ }^{\circ} \mathrm{C}$

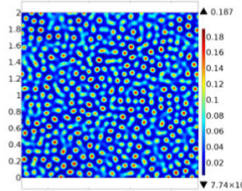

PMB4, Therm.Cond.4 $300 \mathrm{~s}, 140{ }^{\circ} \mathrm{C}$

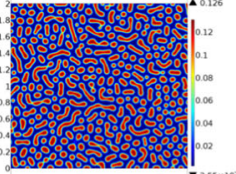

PMB1, Therm.Cond.4 $600 \mathrm{~s}, 140^{\circ} \mathrm{C}$

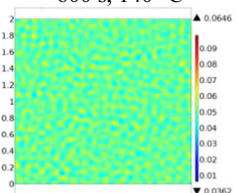

PMB2, Therm.Cond. $600 \mathrm{~s}, 140{ }^{\circ} \mathrm{C}$

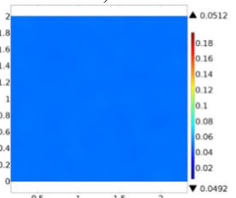

PMB3, Therm. Cond. 4 $600 \mathrm{~s}, 140^{\circ} \mathrm{C}$

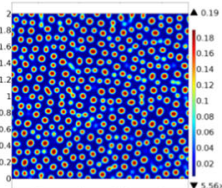

PMB4, Therm.Cond.4 $600 \mathrm{~s}, 140^{\circ} \mathrm{C}$

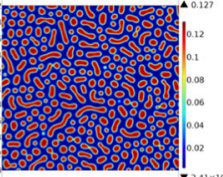

PMB1, Therm Cond 4 $900 \mathrm{~s}, 140{ }^{\circ} \mathrm{C}$

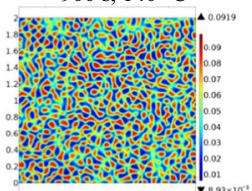

PMB2, Therm.Cond. 4

$900 \mathrm{~s}, 140^{\circ} \mathrm{C}$

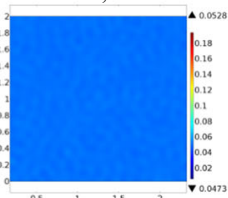

PMB3, Therm. Cond. 4 $900 \mathrm{~s}, 140^{\circ} \mathrm{C}$

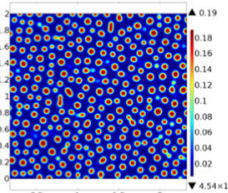

PMB4, Therm.Cond.4 $900 \mathrm{~s}, 140{ }^{\circ} \mathrm{C}$

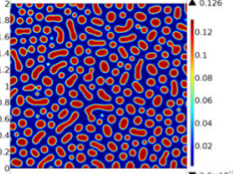

PMB1, Therm. Cond 4 $1800 \mathrm{~s}, 140{ }^{\circ} \mathrm{C}$

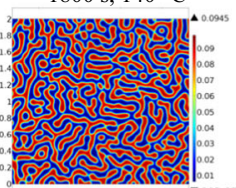

PMB2, Therm. Cond. 4 $1800 \mathrm{~s}, 140^{\circ} \mathrm{C}$

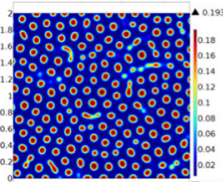

PMB3, Therm. Cond.4 $1800 \mathrm{~s}, 140^{\circ} \mathrm{C}$

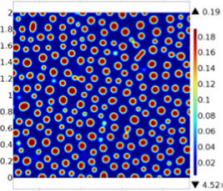

PMB4, Therm.Cond.4 $1800 \mathrm{~s}, 140^{\circ} \mathrm{C}$

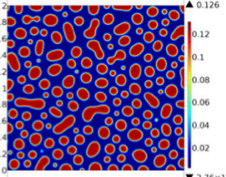

PMB1, Therm Cond 4 $4800 \mathrm{~s}, 140^{\circ} \mathrm{C}$

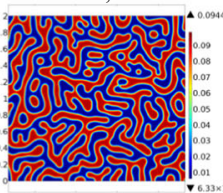

PMB2, Therm.Cond. 4 $4800 \mathrm{~s}, 140^{\circ} \mathrm{C}$

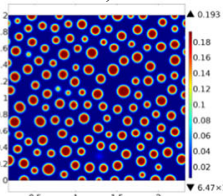

PMB3, Therm. Cond. 4 $4800 \mathrm{~s}, 140^{\circ} \mathrm{C}$

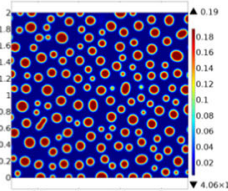

PMB4, Therm. Cond. 4 $4800 \mathrm{~s}, 140^{\circ} \mathrm{C}$

Figure 10 Numerical simulation results with Therm.Cond.4 (fast cooling $8{ }^{\circ} \mathrm{C} / \mathrm{min}$ ).

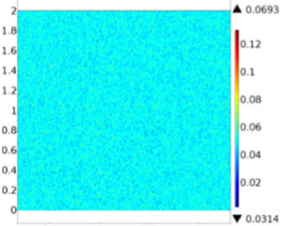

PMB1, Therm. Cond. 5 $0 \mathrm{~s}, 180^{\circ} \mathrm{C}$

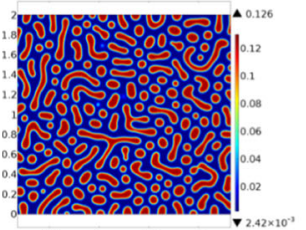

PMB1, Therm.Cond.5 $1500 \mathrm{~s}, 140^{\circ} \mathrm{C}$

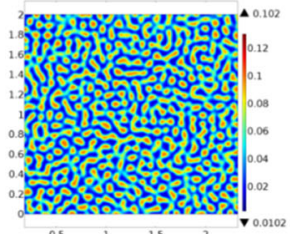

PMB1, Therm.Cond.5 $300 \mathrm{~s}, 170^{\circ} \mathrm{C}$

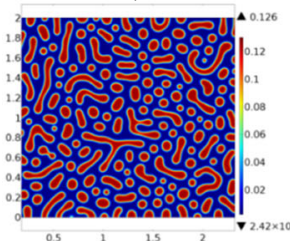

PMB1, Therm.Cond.5 $1800 \mathrm{~s}, 140^{\circ} \mathrm{C}$

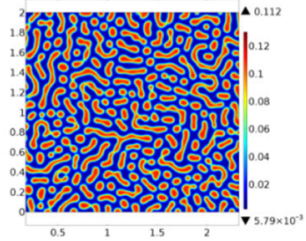

PMB1, Therm. Cond.5 $600 \mathrm{~s}, 160^{\circ} \mathrm{C}$

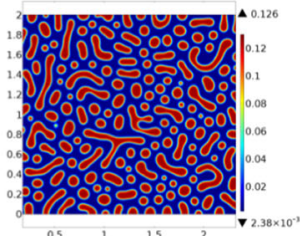

PMB1, Therm. Cond. 5 $2100 \mathrm{~s}, 140^{\circ} \mathrm{C}$

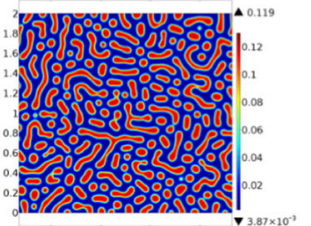

PMB1, Therm. Cond. 5 $900 \mathrm{~s}, 150^{\circ} \mathrm{C}$

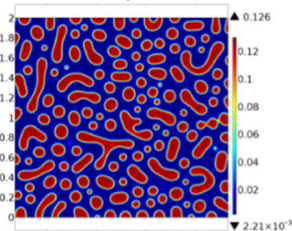

PMB1, Therm. Cond. 5 $3600 \mathrm{~s}, 140{ }^{\circ} \mathrm{C}$

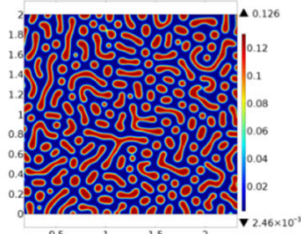

PMB1, Therm.Cond.5 $1200 \mathrm{~s}, 140^{\circ} \mathrm{C}$

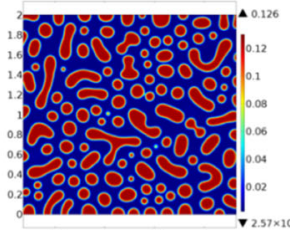

PMB1, Therm. Cond. 5 $4800 \mathrm{~s}, 140{ }^{\circ} \mathrm{C}$

Figure 11 Numerical simulation results of PMB1 with Therm.Cond.5 (slow cooling $2{ }^{\circ} \mathrm{C} / \mathrm{min}$ ).

implemented, the PMB goes through a stability-instability transition around $160{ }^{\circ} \mathrm{C}$. This homogenizes the PMB structure in the beginning of the simulated process and makes the polymer swelling ratio stay on a plateau for some time (longer for slow cooling than fast cooling). The phase separation starts in PMB3 after the homogenization and transition. The bumps on the orange curves in Fig. 15b reflect the starting of the two-phase structures in PMB3 under Therm.Cond.4 and 5. After the bumps, the curves reach almost the same polymer swelling ratio as Therm.Cond.3 (the slow cooling curve still needs some time to reach it). PMB2 is supposed to have experienced the same process. But the dilution parameter of PMB2 is very high at $140{ }^{\circ} \mathrm{C}$ according to Fig. 5. This results in the very small difference between its initial 


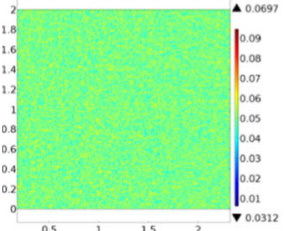

PMB2, Therm.Cond.5 $0 \mathrm{~s}, 180{ }^{\circ} \mathrm{C}$

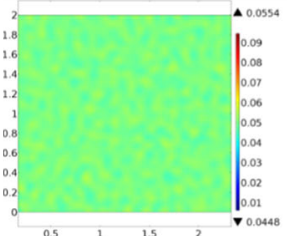

PMB2, Therm.Cond.5 $1500 \mathrm{~s}, 140^{\circ} \mathrm{C}$

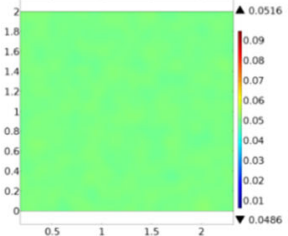

PMB2, Therm.Cond.5 $300 \mathrm{~s}, 170^{\circ} \mathrm{C}$

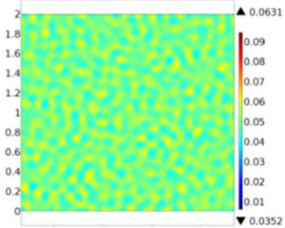

PMB2, Therm. Cond. 5 $1800 \mathrm{~s}, 140{ }^{\circ} \mathrm{C}$

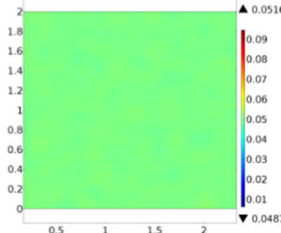

PMB2, Therm.Cond.5 $600 \mathrm{~s}, 160^{\circ} \mathrm{C}$

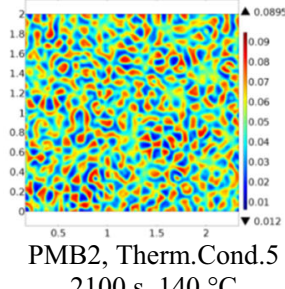

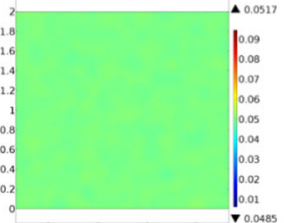

PMB2, Therm. Cond.5 $900 \mathrm{~s}, 150^{\circ} \mathrm{C}$

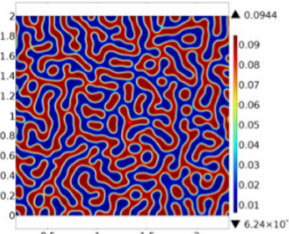

PMB2, Therm. Cond. 5 $3600 \mathrm{~s}, 140^{\circ} \mathrm{C}$

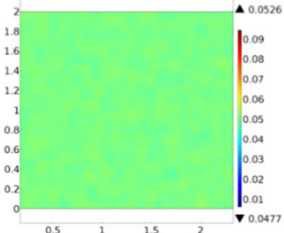

PMB2, Therm.Cond.5 $1200 \mathrm{~s}, 140^{\circ} \mathrm{C}$

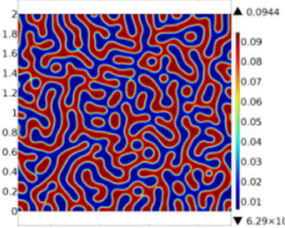

PMB2, Therm.Cond.5 $4800 \mathrm{~s}, 140{ }^{\circ} \mathrm{C}$

Figure 12 Numerical simulation results of PMB2 with Therm.Cond.5 (slow cooling $2{ }^{\circ} \mathrm{C} / \mathrm{min}$ ).

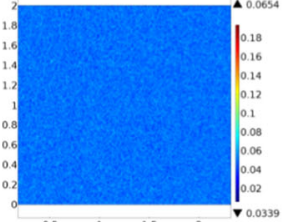

PMB3, Therm.Cond.5 $0 \mathrm{~s}, 180^{\circ} \mathrm{C}$

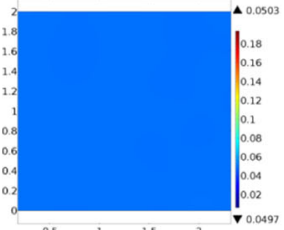

PMB3, Therm. Cond.5 $1500 \mathrm{~s}, 140^{\circ} \mathrm{C}$

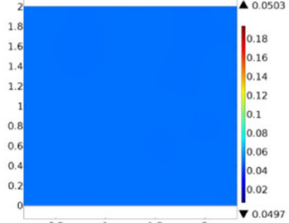

PMB3, Therm. Cond. 5 $300 \mathrm{~s}, 170{ }^{\circ} \mathrm{C}$

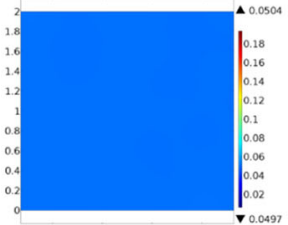

PMB3, Therm.Cond.5 $1800 \mathrm{~s}, 140^{\circ} \mathrm{C}$

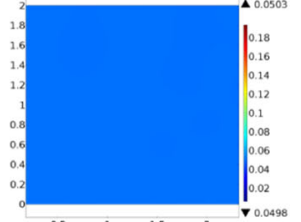

PMB3, Therm. Cond. 5 $600 \mathrm{~s}, 160^{\circ} \mathrm{C}$

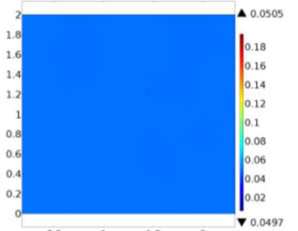

PMB3, Therm. Cond.5 $2100 \mathrm{~s}, 140^{\circ} \mathrm{C}$

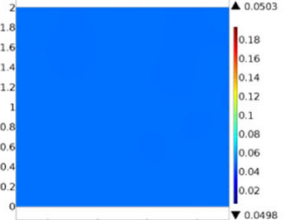

PMB3, Therm. Cond. 5 $900 \mathrm{~s}, 150^{\circ} \mathrm{C}$

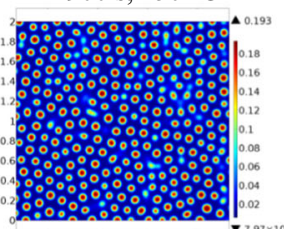

PMB3, Therm Cond 5 $3600 \mathrm{~s}, 140{ }^{\circ} \mathrm{C}$

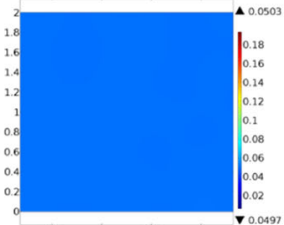

PMB3, Therm. Cond.5 $1200 \mathrm{~s}, 140^{\circ} \mathrm{C}$

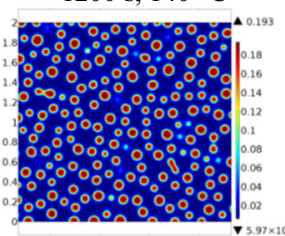

PMB3, Therm.Cond.5 $4800 \mathrm{~s}, 140^{\circ} \mathrm{C}$

Figure 13 Numerical simulation results of PMB3 with Therm.Cond.5 (slow cooling $2{ }^{\circ} \mathrm{C} / \mathrm{min}$ ).

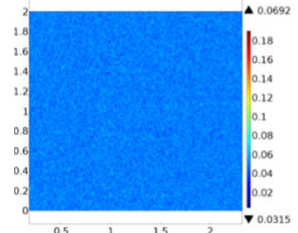

PMB4, Therm. Cond. 5 $0 \mathrm{~s}, 180^{\circ} \mathrm{C}$

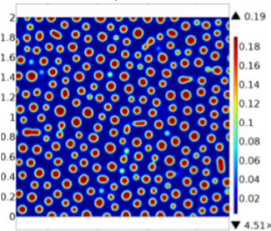

PMB4, Therm. Cond. 5 $1500 \mathrm{~s}, 140^{\circ} \mathrm{C}$

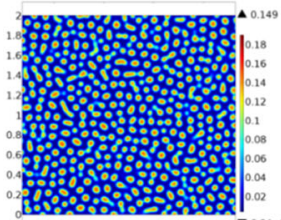

PMB4, Therm. Cond. 5 $300 \mathrm{~s}, 170{ }^{\circ} \mathrm{C}$

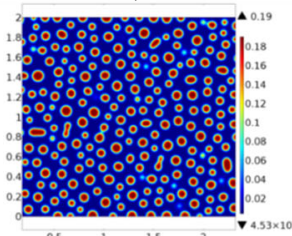

PMB4, Therm. Cond. 5 $1800 \mathrm{~s}, 140^{\circ} \mathrm{C}$

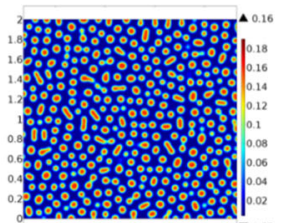

PMB4, Therm. Cond. 5 $600 \mathrm{~s}, 160^{\circ} \mathrm{C}$

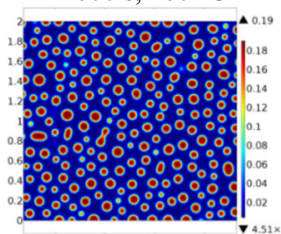

PMB4, Therm. Cond. 5 $2100 \mathrm{~s}, 140^{\circ} \mathrm{C}$

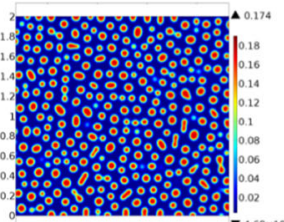

PMB4, Therm. Cond.5 $900 \mathrm{~s}, 150^{\circ} \mathrm{C}$

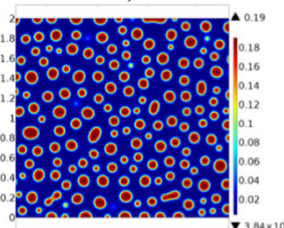

PMB4, Therm. Cond.5 $3600 \mathrm{~s}, 140^{\circ} \mathrm{C}$

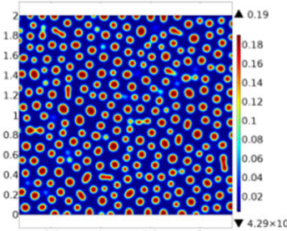

PMB4, Therm.Cond.5 $1200 \mathrm{~s}, 140{ }^{\circ} \mathrm{C}$

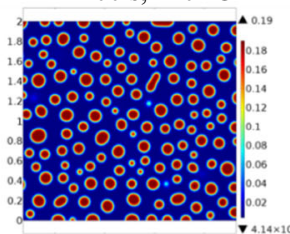

PMB 4 , Therm. Cond.5 $4800 \mathrm{~s}, 140{ }^{\circ} \mathrm{C}$

Figure 14 Numerical simulation results of PMB4 with Therm.Cond.5 (slow cooling $2{ }^{\circ} \mathrm{C} / \mathrm{min}$ ). 
Figure 15 Polymer swelling ratios during PMB phase separation: a for PMB1 and PMB4, $\mathbf{b}$ for PMB2 and PMB3.
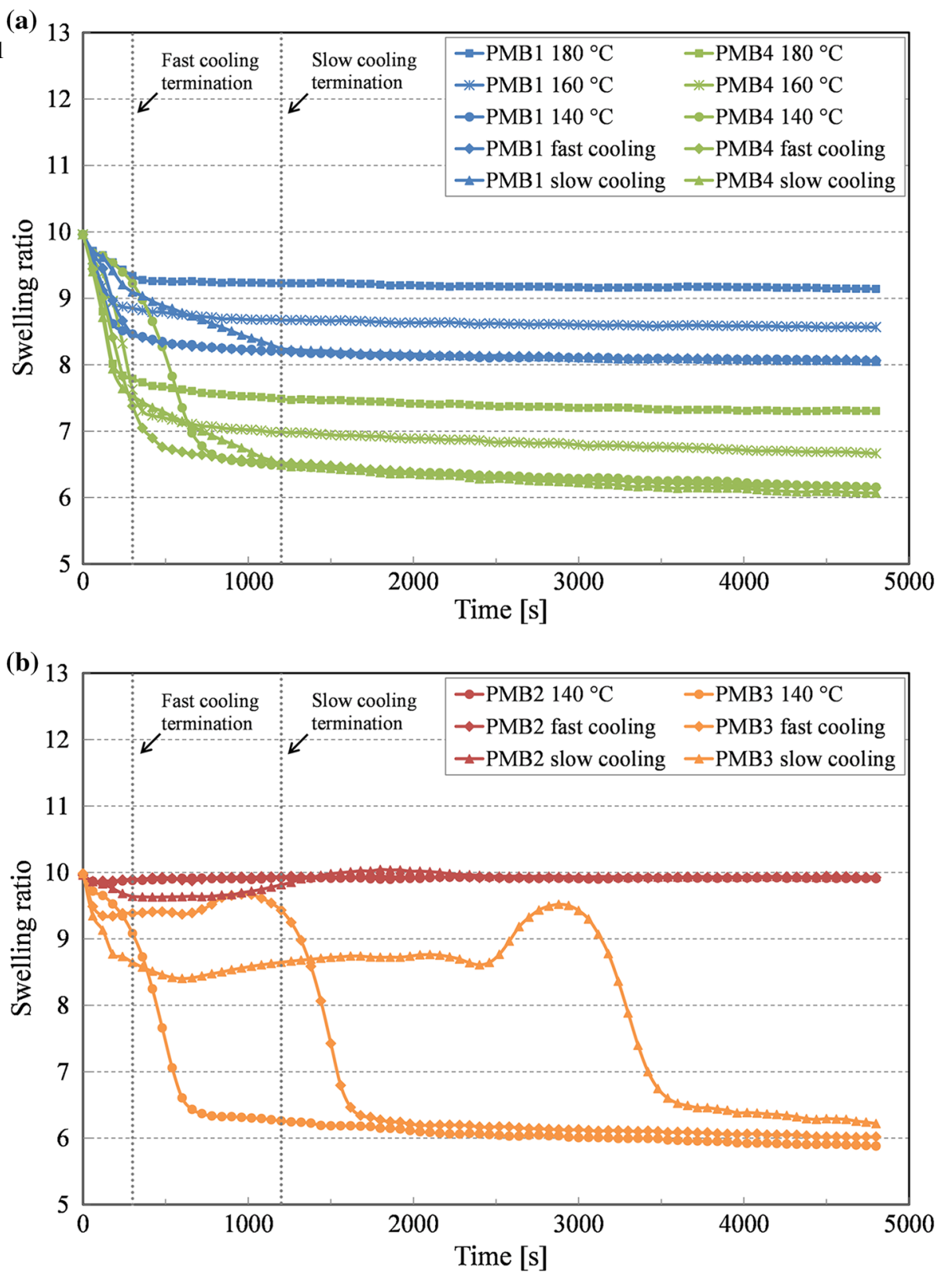

polymer swelling ratio and the equilibrium one at the temperature. As a consequence, the polymer swelling ratio plateaus and bumps are not explicitly shown on the red curves in Fig. 15b. However, the numerical simulation results in the previous sections have indicated the phase separation behaviour of PMB2.

\section{Conclusions}

Aiming to understand the temperature dependency of PMB phase separation behaviour, this paper numerically investigates four PMB binders under five thermal conditions between 180 and $140{ }^{\circ} \mathrm{C}$. For the numerical model, temperature-dependent parameters (mobility coefficients, interaction and dilution parameters) are introduced into a previously proposed phase-field model for PMB phase separation. This makes it possible to investigate the effect of thermal condition on PMB phase separation through a numerical approach. The model is implemented in a finite element software package and calibrated with the experimental observations of the four PMBs. The experimental results are well reproduced by the model, and it is thus believed that the calibrated parameters can represent the four PMBs. On the basis 
of the above-described model and the numerical simulation results, the following conclusions can be drawn:

1. The proposed model is capable of capturing the stability differences among the four PMBs and their microstructure differences between different temperatures. The simulation results indicate that PMBs may show similar microstructures at one temperature, but their phase structures can be completely different at other temperatures. The different material parameters of the PMBs determine the different temperature dependencies of their phase separation behaviour. All these differences are expressed by the model and presented in the numerical simulation results.

2. Since PMB phase separation is a time-dependent microstructure evolution process, the temperature changing rate also has its influence on PMB phase separation behaviour. With cooling implemented, the cooling rate only slightly affects the final PMB microstructures of the 'always-unstable' binders (PMB1 and PMB4). But in the 'stability-transiting' binders (PMB2 and PMB3), a homogenization process occurs during the cooling. This can be assigned to the transition of the PMBs from a thermodynamically stable state at $180{ }^{\circ} \mathrm{C}$ to a thermodynamically unstable state at $140{ }^{\circ} \mathrm{C}$. A slower cooling leads to a more homogenized PMB structure and longer time for the PMB to reach the equilibrium afterwards.

3. For a given $\mathrm{PMB}$, it is the temperature that determines the final values of the polymer swelling ratio and equilibrium phase composition at the end of the simulated process in this paper. A higher temperature leads to a higher polymer swelling ratio, while simulations with the same ending temperature (Therm.Cond.3, 4 and 5) trend to finalize with the same values. This is because the model presented in this paper uses fixed material property parameters for a fixed temperature. However, the process can be more complicated in reality due to the potential effects of the interfacial tension, material viscosity and rheology. More research still needs to be done on this.

4. During the simulated separation process, the polymer swelling ratio of an unstable PMB gradually decreases until the final values are reached at the temperature. This is due to the diffusion of both polymer and bitumen between the two phases. Thermal condition affects the diffusion process and thus the time needed by the PMB to reach the equilibrium state. For the 'alwaysunstable' binders (PMB1 and PMB4), their polymer swelling ratio curves with cooling always follow the middle paths between the 180 and $140{ }^{\circ} \mathrm{C}$ curves at the early stage of the separation. As for PMB2 and PMB3, the stability-instability transition makes the polymer swelling ratio stay on a plateau for some time, because of the homogenization process. After the transition, the PMBs start to follow a representative curve for unstable PMBs.

\section{Acknowledgements}

This study was partially funded by Nordiskt Vägforum (NVF, the Nordic Road Association). The authors greatly appreciate the financial support. The first author gratefully acknowledges the scholarship from the China Scholarship Council.

\section{Compliance with ethical standards}

Conflict of interest The authors declare that they have no conflict of interest.

Open Access This article is distributed under the terms of the Creative Commons Attribution 4.0 International License (http://creativecommons.org/licen ses/by/4.0/), which permits unrestricted use, distribution, and reproduction in any medium, provided you give appropriate credit to the original author(s) and the source, provide a link to the Creative Commons license, and indicate if changes were made.

\section{References}

[1] Lesueur D, Gerard JF, Claudy P, Létoffé JM, Martin D, Planche JP (1998) Polymer modified asphalts as viscoelastic emulsions. J Rheol 42(5):1059-1074

[2] Mouillet V, Lamontagne J, Durrieu F, Planche JP, Lapalu L (2008) Infrared microscopy investigation of oxidation and phase evolution in bitumen modified with polymers. Fuel 87(7):1270-1280 
[3] Alonso S, Medina-Torres L, Zitzumbo R, Avalos F (2010) Rheology of asphalt and styrene-butadiene blends. J Mater Sci 45(10):2591-2597

[4] Spadaro C, Plummer CJ, Månson JAE (2011) Thermal and dynamic mechanical properties of blends of bitumen with metallocene catalyzed polyolefins. J Mater Sci 46(23):7449-7458. doi:10.1007/s10853-011-5711-5

[5] Zhao X, Wang S, Wang Q, Yao H (2016) Rheological and structural evolution of SBS modified asphalts under natural weathering. Fuel 184:242-247

[6] Zhu J, Birgisson B, Kringos N (2014) Polymer modification of bitumen: advances and challenges. Eur Polym J 54:18-38

[7] Polacco G, Filippi S, Merusi F, Stastna G (2015) A review of the fundamentals of polymer-modified asphalts: asphalt/ polymer interactions and principles of compatibility. Adv Colloid Interface Sci 224:72-112

[8] Zhu J, Kringos N (2015) Towards the development of a viscoelastic model for phase separation in polymer-modified bitumen. Road Mater Pavement 16(S1):39-49

[9] Zhu J, Lu X, Kringos N (2016) Experimental investigation on storage stability and phase separation behaviour of polymer-modified bitumen. Int J Pavement Eng. doi:10. 1080/10298436.2016.1211870

[10] Soenen H, Lu X, Redelius P (2008) The morphology of bitumen-SBS blends by UV microscopy: an evaluation of preparation methods. Road Mater Pavement 9(1):97-110

[11] Soenen H, Lu X, Redelius P (2009) The morphology of SBS modified bitumen in binders and in asphalt mix. In: Loizos A, Partl MN, Scarpas T, Al-Qadi IL (eds) Advanced testing and characterization of bituminous materials: proceedings of the 7th international RILEM symposium ATCBM09, Rhodes, Greece, 27-29 May, 2009. CRC Press, Leiden, pp 151-160

[12] Lu X, Redelius P, Soenen H (2010) SBS modified bitumens: does their morphology and storage stability influence asphalt mix performance? In: Proceedings of the 11th international conference on asphalt pavements, Nagoya, 1-6 Aug 2010. International Society for Asphalt Pavements, Lino Lakes, pp 1604-1613

[13] Zhu J, Balieu R, Lu X, Kringos N (2016) Influence of thermal history on phase separation in polymer modified bitumen: a numerical approach. In: Pauli T, Planche JP (eds) Proceedings of the ISAP 2016 symposium, Jackson, 18-21 July 2016. International Society for Asphalt Pavements, Lino Lakes, paper 8

[14] Zhu J, Lu X, Balieu R, Kringos N (2016) Modelling and numerical simulation of phase separation in polymer modified bitumen by phase-field method. Mater Des 107:322-332

[15] Hou Y, Wang L, Yue P, Pauli T, Sun W (2014) Modeling mode I cracking failure in asphalt binder by using nonconserved phase-field model. J Mater Civ Eng 26(4):684-691
[16] Hou Y, Wang L, Pauli T, Sun W (2015) Investigation of the asphalt self-healing mechanism using a phase-field model. J Mater Civ Eng 27(3):04014118

[17] Bhasin A, Ganesan V (2015) Preliminary investigation of using a multi-component phase field model to evaluate microstructure of asphalt binders. Int J Pavement Eng. doi:10.1080/10298436.2015.1065998

[18] Chen LQ (2002) Phase-field models for microstructure evolution. Annu Rev Mater Res 32(1):113-140

[19] Moelans N, Blanpain B, Wollants P (2008) An introduction to phase-field modeling of microstructure evolution. Calphad 32(2):268-294

[20] Cahn JW, Hilliard JE (1958) Free energy of a nonuniform system. I. Interfacial free energy. J Chem Phys 28(2):258-267

[21] Wen YH, Simmons JP, Shen C, Woodward C, Wang Y (2003) Phase-field modeling of bimodal particle size distributions during continuous cooling. Acta Mater 51(4):1123-1132

[22] Ertl H, Dullien FAL (1973) Self-diffusion and viscosity of some liquids as a function of temperature. AIChE J 19(6):1215-1223

[23] Holz M, Heil SR, Sacco A (2000) Temperature-dependent self-diffusion coefficients of water and six selected molecular liquids for calibration in accurate ${ }^{1} \mathrm{H}$ NMR PFG measurements. Phys Chem Chem Phys 2(20):4740-4742

[24] Russell TP, Hjelm RP Jr, Seeger PA (1990) Temperature dependence of the interaction parameter of polystyrene and poly(methyl methacrylate). Macromolecules 23(3):890-893

[25] Chremos A, Nikoubashman A, Panagiotopoulos AZ (2014) Flory-Huggins parameter $\chi$, from binary mixtures of Lennard-Jones particles to block copolymer melts. J Chem Phys 140(5):054909

[26] Brûlé B, Brion Y, Tanguy A (1988) Paving asphalt polymer blends: relationships between composition, structure and properties. J Assoc Asphalt Paving Technol 57:41-64

[27] Ubachs RLJM, Schreurs PJG, Geers MGD (2004) A nonlocal diffuse interface model for microstructure evolution of tin-lead solder. J Mech Phys Solids 52(8):1763-1792

[28] Badalassi VE, Ceniceros HD, Banerjee S (2003) Computation of multiphase systems with phase field models. J Comput Phys 190(2):371-397

[29] Anders D, Weinberg K (2012) Thermophoresis in binary blends. Mech Mater 47:33-50

[30] Anders D, Weinberg K, Reichardt R (2012) Isogeometric analysis of thermal diffusion in binary blends. Comp Mater Sci 52(1):182-188

[31] Tanaka H, Araki T (1997) Phase inversion during viscoelastic phase separation: roles of bulk and shear relaxation moduli. Phys Rev Lett 78(26):4966-4969 
[32] Araki T, Tanaka H (2001) Three-dimensional numerical simulations of viscoelastic phase separation: morphological characteristics. Macromolecules 34(6):1953-1963

[33] Zhou D, Zhang P, Weinan E (2006) Modified models of polymer phase separation. Phys Rev E 73(6):061801

[34] Kringos N, Schmets A, Scarpas A, Pauli T (2011) Towards an understanding of the self-healing capacity of asphaltic mixtures. Heron 56(1/2):45-74
[35] Fuentes-Audén C, Sandoval JA, Jerez A, Navarro FJ, Martínez-Boza FJ, Partal P et al (2008) Evaluation of thermal and mechanical properties of recycled polyethylene modified bitumen. Polym Test 27(8):1005-1012

[36] Sengoz B, Isikyakar G (2008) Analysis of styrene-butadiene-styrene polymer modified bitumen using fluorescent microscopy and conventional test methods. J Hazard Mater 150(2):424-432 